Article

\title{
Cleaning up Forever Chemicals in Construction: Informing Industry Change
}

\author{
Kurt Chamberlain ${ }^{1}$, Bethanie Storey ${ }^{1}$, Jayden Brown ${ }^{1}$, Scott Rayburg ${ }^{1, *}$, John Rodwell ${ }^{2}{ }^{(1)}$ and Melissa Neave ${ }^{3}$ \\ 1 Department of Civil and Construction Engineering, Swinburne University of Technology, \\ Hawthorn, VIC 3122, Australia; 100574178@student.swin.edu.au (K.C.); \\ 100588658@student.swin.edu.au (B.S.); 101093438@student.swin.edu.au (J.B.) \\ 2 Department of Management \& Marketing, Swinburne University of Technology, \\ Hawthorn, VIC 3122, Australia; jrodwell@swin.edu.au \\ 3 School of Global, Urban and Social Studies, RMIT University, Melbourne, VIC 3001, Australia; \\ melissa.neave@rmit.edu.au \\ * Correspondence: srayburg@swin.edu.au; Tel.: +61-3-92144944
}

Citation: Chamberlain, K.; Storey, B.; Brown, J.; Rayburg, S.; Rodwell, J.; Neave, M. Cleaning up Forever Chemicals in Construction: Informing Industry Change. Sustainability 2022, 14, 2854. https:// doi.org/10.3390/su14052854

Academic Editors: Antonio Caggiano and Guillaume Habert

Received: 31 December 2021 Accepted: 25 February 2022 Published: 1 March 2022

Publisher's Note: MDPI stays neutral with regard to jurisdictional claims in published maps and institutional affiliations.

Copyright: (c) 2022 by the authors. Licensee MDPI, Basel, Switzerland. This article is an open access article distributed under the terms and conditions of the Creative Commons Attribution (CC BY) license (https:// creativecommons.org/licenses/by/ $4.0 /)$.

\begin{abstract}
Per- and polyfluorinated alkyl substance (PFAS) contamination has been found in the construction spoil of many major projects, and there is growing concern about the health and environmental implications of these "forever" chemicals. In a context where construction and tunneling have experienced substantial growth, Australia and other countries are still developing their PFAS management. This study used convergent interviews to surface the key common issues that are associated with the management of PFAS contamination in the construction industry. The construction industry appears stuck in their ways and extremely financially driven. Regulation is not working because of poor enforcement and policing from the Environmental Protection Agency (EPA). The EPA could look to employ individuals with more construction industry experience in order to become a strong regulator in the industry, as well as to streamlining decision-making processes, while maintaining quality. To speed up changes in the management of PFASs within the construction industry, large organizations could be targeted by the relevant sustainability rating scheme, and there could be further use of the alliance models to research, develop, and implement PFAS treatment methods.
\end{abstract}

Keywords: PFAS; remediation; toxic soil; tunneling; convergent interviewing; spoil

\section{Introduction: Per- and Polyfluorinated Alkyl Substances}

Per- and polyfluorinated alkyl substances (PFASs) are a chemical family that is hailed as a major breakthrough because of the pronounced ability of the compounds to repel water, dirt, and grease, as well as its ability to produce an extremely high level of temperature resistance by forming a film that surrounds other compounds [1]. However, once PFAS substances are in soils, they remain there forever and, hence, they are often called "forever chemicals" [2].

Countries around the world have been taking steps to manage PFASs, although they are still working towards an inventory of PFASs around the globe [3]. The Stockholm Convention on Persistent Organic Pollutants has established global monitoring plans, including United Nations Environmental Program (UNEP) programs, to monitor the PFASs in surface waters in developing countries (e.g., [4]).

The countries of the world are only beginning to monitor and manage PFASs. For example, the key forms of PFASs were listed on the Stockholm Convention after Australia ratified the initial agreement; Australia is yet to ratify the revised chemical listings. However, there is concern that Australia must be able to meet the associated management obligations [5]. 
The need for the development of PFAS management capabilities is critical because PFASs are the most persistent synthetic chemicals discovered to date, and they are not only persistent in the environment, but also in the human body [6]. Furthermore, as communities become more aware and more educated about PFAS-contaminated soils, there are increasing calls for action to be taken with regard to this detrimental contaminant during construction projects [7].

This paper will review how the construction industry is booming with the demand for infrastructure, which often results in large amounts of spoil that may be contaminated by PFASs, using Australia, and particularly Victoria, as an example. Australia, and particularly Victoria, are an interesting focus because, despite being in an advanced developed economy, the industry is not remediating PFAS spoil, and there is little in the way of regulations that require or detail the handling or remediation of PFASs. The paper will then review the potential roles of regulations and industry schemes that could directly impact PFAS management. The study will finally investigate the key issues that are associated with the management of PFAS contamination in the construction industry in Victoria, where millions of tons of contaminated spoil present a challenge to the sustainability of the industry.

\subsection{PFASs within the Construction Industry}

In the coming years, many countries will have dramatic increases in significant tunneling projects throughout major cities and population hubs. For example, in Australia, there are currently 18 major tunneling projects in the expression-of-interest or tender phases, including: the Snowy Hydro Project 2.0 in New South Wales, which will use underground tunneling to link dams and to generate power, creating 750,000 cubic meters of fill [8]; sections of the Forrestfield Airport Link in Western Australia, with $8.5 \mathrm{~km}$ of rail tunnels, which is expected to generate one and a half to two million tons of fill [9], and the North East Link in Victoria, with two six-kilometer twin tunnels [10]. In most of these projects, PFASs will be encountered when tunneling [11], which leads to an extraordinary amount of PFAS-contaminated construction waste to be disposed of.

One of these new major infrastructure projects, the West Gate Tunnel project in Melbourne, is currently under construction, and is estimated to excavate and expose 1.5 million cubic meters of dirt and rock through the use of multiple tunnel-boring machines [10]. Excessive PFAS contamination levels in the construction spoil were encountered during the early construction stages of the West Gate Tunnel Project, and this delayed the tunneling work until a solution for the contamination issue was developed [7].

The current practices in the management of PFAS-contaminated spoil on this project are perceived to be effectively nonexistent, with the contractors unable to move the contaminated soil to any dumping facilities because the PFASs lack an official classification by the EPA for the reuse of PFAS-contaminated construction spoil [7].

The only safety measure in place by the contractors for this PFAS-contaminated tunnel spoil is the lining of contaminated waste stockpiles with black tarpaulins, mainly to prevent the airborne spread of contamination [12]. The transfer of these waste products to landfill sites with PFAS contamination levels over 100 times the safety level for drinking water will only create further complications for future generations, who will have to remove these contaminants from the area, with their high levels of leachability likely to cause the surrounding areas to be potentially uninhabitable [12].

PFAS treatment options currently exist (e.g., see Appendix A for a brief review), albeit with some limitations, but they are not currently being used, or even trialed, in the construction and tunneling industries in Australia. The lack of action may be because the industry itself has no imperative to treat PFAS-contaminated waste, and the cost of such treatment is rarely, if ever, included in the contracts for infrastructure projects. That is, the construction industry appears to require appropriate regulation and/or industry mechanisms to prompt them to manage PFASs. Therefore, this paper will next overview the relevant PFAS regulations that impact construction in Australia, and particularly the 
state of Victoria, and it will then review the industry systems that may also be relevant to the management of PFAS contamination in construction.

\subsection{PFAS Regulations: The Environmental Protection Authority in Victoria and Beyond}

The principal government organization that is tasked with the coordination of contaminated waste management in the environment for the state of Victoria, in Australia, including the development of new regulations surrounding PFAS contamination, is the Environmental Protection Authority (Victoria). The Environmental Protection Authority (EPA) is an environmental regulator that acts as an independent statutory authority, whose role involves reducing the impacts of pollution and waste on the environment [13]. The EPA had been operating in accordance with the Environmental Protection Act 1970 (the Act); however, from 1 July 2021, the Environmental Protection Act 2018 (the Amendment Act) came into effect. This change in legislation is the first major review of the Environmental Protection Act since the EPA began operations in 1971 [14].

With the replacement of the Environmental Protection Act, the EPA have adjusted their organizational structure. The most significant of these changes is the move to allow the community to voice their concerns with regard to environmental issues [15]. Furthermore, the EPA introduced a clearer and stricter penalty structure for those responsible for the improper stockpiling and improper disposal of PFAS chemicals [16].

The Victorian Government also announced more funding to provide additional support for the management and policing of hazardous waste materials, including the introduction of a waste crime prevention inspector unit [14]. Although these EPA reforms are a step in the right direction, there is still no explicit mention of PFASs or other contamination from construction waste.

More broadly, there is no commonwealth (Australia-wide) legislation that has the sole purpose of determining the best overall practice for the control, handling, and disposal of PFAS-contaminated soil within the construction industry. Consequently, such regulations and recommendations are left in the hands of the EPA organizations in each state. In 2017, the heads of the EPAs across Australia and New Zealand, in collaboration with the Australian government, produced the PFAS National Environmental Management Plan (PFAS NEMP), a national framework based on the recommendations of the best methods to manage PFAS contamination and mitigate the risks to human health and the environment. The plan also provides a guide for the EPAs in each jurisdiction to create regulations of their own to assist in managing the issue [17]. The next key stakeholder is the construction industry itself.

\subsection{Industry Schemes That Could Impact PFAS Management}

The construction industry has been making some efforts at more sustainable construction within the relevant national regulations, including through the introduction of the Civil Engineering Environmental Quality Assessment and Award Scheme, which was developed in the United Kingdom in 2003 by The Institute of Civil Engineers [18]. A similar scheme was established in Australia in 2008, and, in 2012, its name was changed to, the Infrastructure Sustainability Council of Australia (ISCA). The aim of the scheme is to promote and endorse a high level of environmental, economic, and social benefits, in all aspects of civil engineering projects, through the use of a standardized rating system [18-20].

The ISCA provides education, training, and the nationally recognized infrastructure sustainability (IS) rating scheme. Any infrastructure project can partake in the IS rating scheme; however, if the capital value of the project is over AUD 20 million, then an IS rating scheme must be part of all of the design, construction, and maintenance contracts [21].

The rating scheme was designed to evaluate and certify contractors on the basis of a range of criteria, which are detailed in the Infrastructure Sustainability Rating Tool Technical Manual [21,22]. Generally, for a construction project that is required to achieve an IS rating, the contract will stipulate the criteria that must be met, and what rating each criterion must achieve in order to receive a financial reward [18]. Typically, the IS rating scheme 
evaluates and certifies a project's performance against a range of set criteria, which include, but are not limited to, the use of sustainable resources, ecology, stakeholder and community involvement, community impact, and land use and climate change resilience, where each item is given a score, which are then combined into an overall IS rating for the project [23]. If the design and/or construction entities meet or exceed the project's predetermined IS rating, then they are able to be rewarded with government grants to outlay against the costs that are involved in the implementation of a more sustainable project [18]. Unfortunately, however, this rating scheme does not currently provide any additional points towards a project's overall sustainability rating if the civil construction contractor were to treat PFAS-contaminated soils in an environmentally friendly manner [24], although the system implies that PFAS-oriented criteria could be added to the process.

In summary, there is little PFAS-oriented regulation in Australia, and little motivation for the construction industry to spontaneously manage PFASs, which, together, has led to PFAS contamination often being poorly managed. Consequently, this study investigates the key issues that are associated with the management of PFAS contamination in the construction industry in Australia, and particularly in Victoria, where millions of tons of contaminated spoil present a challenge to the sustainability of the industry.

\section{Materials and Methods}

The procedure for conducting the interviews was a version of convergent interviewing. Convergent interviewing is a useful, inductive, and rigorous qualitative approach for studying under-researched areas and both practical and academic projects [25], as well as particularly complex areas that are often considered to be "wicked problems" [26].

When faced with complex or "wicked" problems, a powerful diagnostic tool that generates actionable results is convergent interviewing. Convergent interviewing is a method that takes a process-oriented action-enabling approach to change [27]. The use of a systematic process to source information from experts with a breadth of perspectives means that the results have a relevance and authenticity that are powerful for later intervention design [26]. The tool has been used to inform successful organizational changes for several decades (e.g., change programs in the Australia Post since the early 1970s; see [27]), as well as for informing changes in the public sector [28].

The focus of convergent interviews is on the issues that are raised in common within a round of interviews and on the issues that converge across rounds, and not specifically on any one point raised by any one interviewee. The method, and its considerations, are detailed in [27]. For a recent detailed outline of the processes involved in the method, see [29]. A further benefit of convergent interviewing is that the results can inform change planning by surfacing and organizing issues that are often represented from a systems perspective [26].

Each round consisted of two interviews. After each round of interviews, the content of that round's interviews was analyzed for the issues in common. If the interviewees in a round each raised a particular issue or relationship and agreed about its role in the management of PFASs, the researchers generated a probe question to tease out the possible exceptions to that relationship. If a round's interviewees each raised an issue, but disagreed about its nature, the researchers generated a probe question for the later rounds of the interviews that would explore the differences. Throughout the convergent interviewing process, if an issue was raised by only one interviewee, then that issue was not the basis of the probe questions. The later rounds of the interviewing process asked the core question and the probe questions. Consequently, an expanding list of key issues and their relationships was generated.

The interviewer concludes the interviews with a summation of the key issues and clarifies any points of uncertainty or ambiguity with the participant. Unlike standard interviews that continue until some form of "saturation", convergent interviews have a built-in endpoint, whereby the process stops after there are two rounds with no new common issues, which is often reached quickly. To investigate how the management of PFASs is 
considered within the construction industry within Victoria, Australia, 12 interviews with experts were undertaken.

A defining characteristic of the convergent interviews (per [27]) is that the sequence of interviewees being interviewed was on the basis of their degree of expertise on the specific question of interest (the issues associated with the management of PFASs in construction in Victoria), as well as on the degree to which their knowledge was different to the other subject-matter-expert interviewees. That is, the interviewees were not selected to be representative, nor because of their role. The interviewees in the first few rounds had 25 years or more of experience, and included people from regulatory enforcement, as well as senior managers and experts in construction; however, they were selected because of their specific expertise on the management of PFASs.

The people with the most expertise on the topic were interviewed in the first round, but they were chosen to be as different as possible from each other, and the following interviewees were placed into rounds on the basis of a descending order of expertise, and on being different from their pairs and predecessors [27]. The first nine interviews were conducted online, and they followed a classic convergent interviewing approach, which was already converging on a set of common issues. The following last few interviews, on the relatively consistent issues arising from the convergence of the first nine interviews, were more akin to confirmatory meetings, at least, in part, because of their online nature, which was due to COVID-19 restrictions.

Convergent interviewing has many mechanisms built into its processes in order to enhance its rigor [25,27]. For example, the processes ensure that every interview starts with the same question, which enables every interviewee to contribute without being influenced by the interviewer or other interviewees, which thereby provides uncontaminated information. The process also has checks within a round, and across rounds, with regard to the reliability and validity of the issues raised. The convergent interviewing process actively pursues disconfirming evidence by, among other design characteristics, not only having interviewees who are as different as possible from each other within a round, but also by employing probe questions that seek to explain the disagreements in perspective with regard to the common issues [26].

A useful approach for understanding the often-complex results of convergent interviewing is systems thinking, particularly using influence diagrams [30]. That is, the key common issues that are raised by the convergent interviewing processes reflect the system being studied, and the results are usually summarized as a set of relationships in a systems model [28].

\section{Results}

The key common issues that were raised from the convergent interviews and their interrelationships are summarized in the systems influence diagram in Figure 1. The following text will work through the key flows of the relationships represented in Figure 1. Starting at the top and middle, the results note the infrastructure construction boom and the need to address PFAS contamination, particularly that which is due to the reliance on tunneling. The results reflect the review above in that the current management of PFASs was seen as deficient, despite the acknowledged environmental, health, and community impacts. The results indicate that the experts were aware of the options that were available for treating PFASs (summarized in Appendix A), but they noted that the construction industry was slow to change, and that it was indeed seen to be archaic in many of its approaches.

In digging deeper into the key common issues holding up industry change, a key inflection arose in terms of the drivers, where there was a recognition of the financial focus of the industry, and where there were separate and largely nonfinancial drivers, such as regulation. That is, one of the significant barriers to change and the industrywide implementation of PFAS remediation methods was the construction sector being an industry that is focused heavily on financial issues, and the consequent challenges to 
spontaneously implementing sustainable PFAS remediation methods because of both the costs and the mindset of large civil construction contractors.

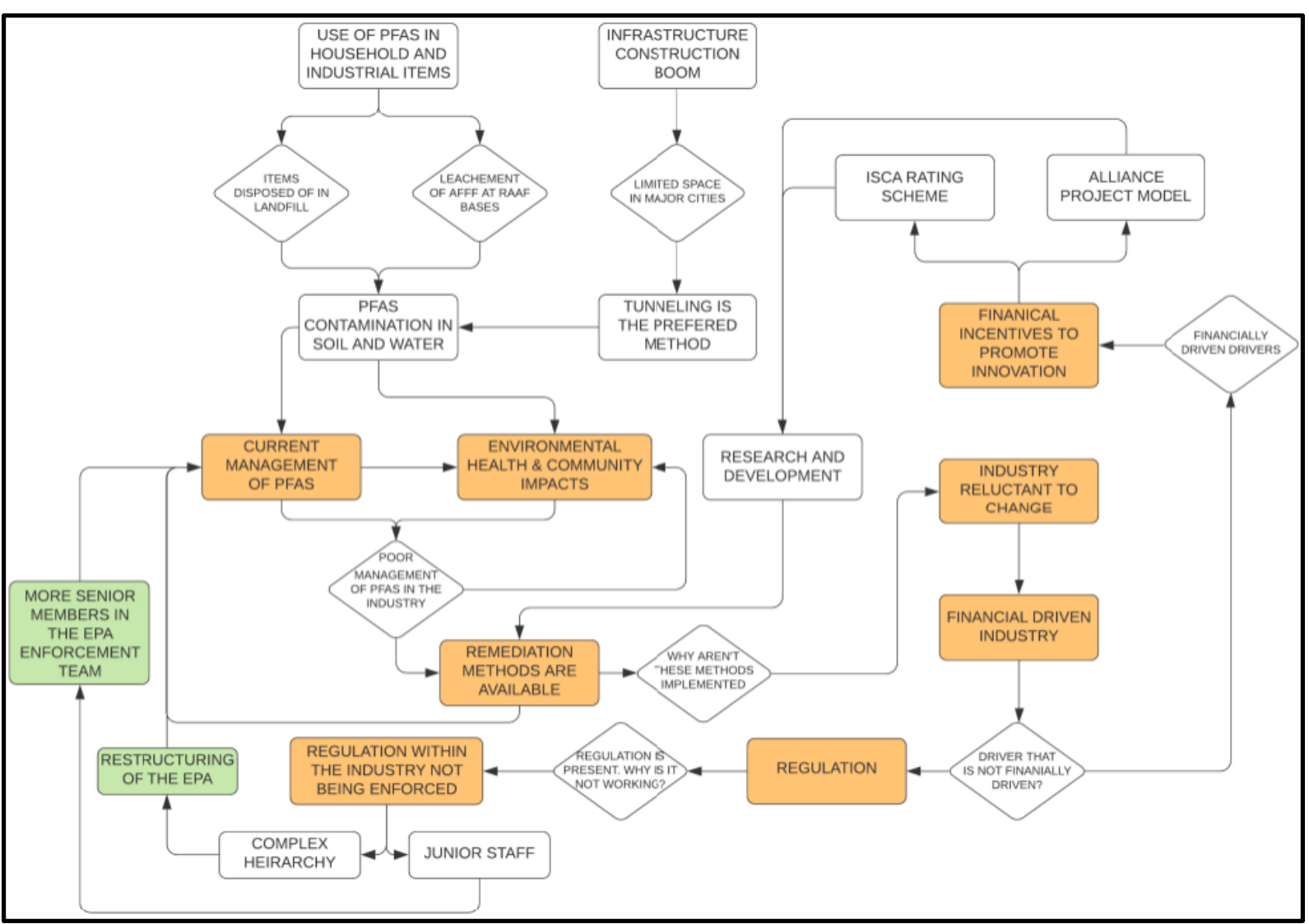

Figure 1. An influence diagram summarizing the results from the convergent interviews.

Once the issues in the systems model begin to go in various directions, a few key points of leverage arise. First, in terms of regulation, is the need to sharpen up the efforts of the EPA, and second are two mechanisms that may act to raise awareness in the industry with regard to the need to address PFAS contamination through both operational means, such as the IS rating scheme, or strategic means, such as the use of alliance models.

These results indicate that, to produce change within the construction industry, drivers need to be developed that are not financially oriented in order to ensure that all of the organizations are on a level playing field and that all are equally competitive. Regulatory drivers could be an initial focus of the implementation of the change required; however, given that regulatory drivers are already present within the industry, the themes that arose were more about why this current regulation was failing to generate recommendations for progression. It was proposed that the regulatory approach was not working in the construction industry because of poor enforcement and policing from the environmental regulatory body, the EPA. Further analysis determined that the lack of policing and enforcement was due to junior members of the EPA, with little or no experience in the industry, being employed to enforce regulation on large organizations, as well as to the EPA having a complex hierarchy for decision making.

The results about the EPA's inability to effectively police PFAS contamination is not only exacerbating problems within the environment, but also creating them. With the introduction of the new Environmental Act, there is still no regulation around the disposal and handling of PFASs being implemented by the EPA. Instead, the EPA aims to introduce a stricter penalty system for those responsible for the illegal stockpiling and disposal of PFAS chemicals. The more stringent penalty structure has seen the EPA putting more 
responsibility on the people of the community, rather than on themselves. That is, the results from the interviews show that the EPA's oversight in auditing has not been strong enough.

The IS rating scheme is currently considered to be only suitable for large-scale projects, which are usually contracted to Tier- 1 and -2 construction companies that have ample resources. Achieving the ISCA rating requires a lot of resources, which is difficult for smaller companies that may not have sophisticated enough systems in place to meet the requirements of the ISCA. For some small companies, the financial reward for meeting the requirements could be less than not putting the resources into achieving the rating, which suggests that the IS rating may need to be adjusted, or may need to have an alternative pathway, for smaller projects.

Furthermore, adding a PFAS requirement to the criteria could be productive in the development of best practices for contractors for treating PFASs. A possible accelerator for the effectiveness of the IS approach that may fast-track innovation would be to increase the financial incentive given to contractors, particularly to better fund the research and development of treatments that are suited to both the more extensive and smaller-scale projects.

The second mechanism for encouraging change suggests that, in order to catalyze innovation, more projects should be awarded under an alliance model, rather than constructonly or design-and-construct contracts, as has been common in the Victorian civil construction industry for many years. The alliance project delivery method aims to create equal risk and equal reward for all parties involved [31]. The collaboration between the government, the design contractor, and the construction contractor, help to develop joint expectations for the performance measures on the project, assists in moving away from the previous focus of profitability, and establishes a best outcome for all to focus on [31].

\section{Discussion}

The convergent interviewing processes surfaced issues that are associated with the management of PFAS contamination in the construction industry, and they suggest a set of recommendations for improvements. The construction industry appears to be stuck in their ways and extremely financially driven. Regulation was not working because of poor enforcement and policing from the Environmental Protection Agency (EPA), with junior members of the EPA being tasked with enforcing regulation, and a complex decisionmaking hierarchy. To speed up the changes in the management of PFASs within the construction industry, large organizations could be targeted by the relevant sustainability rating scheme, and there could be further use of alliance models to research and develop PFAS treatment methods.

The EPA could look to employ individuals with more construction industry experience in order to become a strong regulator in the industry and to improve their reputation among contractors. Furthermore, the results suggest that the EPA review their internal leadership hierarchy for decision making to determine if it can be streamlined in order to decrease the time for a decision to be made, while simultaneously not impacting the decision's quality.

Two mechanisms that may be seen more positively by the industry, and that may act to raise awareness of the need to address PFAS contamination, are through operational tools, such as the IS rating scheme, or through strategic approaches, such as the use of alliance models. That is, to speed up the changes to the PFAS management within the construction industry, large-scale organizations could be targeted in the implementation of the ISCA rating scheme, and there could be more widespread use of alliance models to enhance the research and development of the treatment and reuse methods for PFAS contamination in construction spoil. The infrastructure sustainability rating tools provide the grounds for change within the construction industry, with these tools providing awareness of the sustainability issues within large-scale projects, that were then also resolved in other projects that did not include any sustainability ratings [32].

More strategically, alliance models change the focus from profitability, and more effort can be focused on innovation, such as new practices that could see improvements in the sustainability of projects. With all parties involved in the delivery of a project, the financial 
risk associated with changing practices is distributed, and this facilitates an environment where the construction contractors have the ability to innovate. Therefore, it will be more likely that contractors, through obligation and less financial risk, will be able to develop more sustainable construction practices, and will have the potential to modernize the industry to suit the current environmental demands. The use of both the ISCA and alliance models in the Victorian construction industry will help to cultivate a change of attitude among the contractors, and it will create a move away from doing things the "old way", or for the least amount of money, towards looking for ways to innovate.

A number of factors may suggest limitations for the results. Initially, because of the current unprecedented times due to the COVID-19 virus, all of the interviews completed within this research were concluded over several different Internet video chat applications. Interviewing in this manner limited the investigators in many ways, one being that not all of the industry professionals had access to a stable Internet connection, which caused some difficulty, but a more important issue was that using video chat can limit the rapport that can be built during in-person interviews. A further complicating factor is that some interviews may not have been as powerful as they usually are because of a current court case between Transurban, the joint building venture of CPB Contractors and John Holland, and the Victorian Government, which may have led to some interviewees self-censoring their responses. The nature of convergent interviews, where the focus is on the common issues that arise across multiple interviewees, should have limited the impact of these rapport and self-censoring possibilities, but they are noted as possible limitations.

This study's location in Australia, with a slight emphasis on Victoria, may also be a limitation of the results. However, while the content issues in the results may not always be immediately transferable to other contexts, they should provide stimuli for comparable contexts overseas. Alternatively, this project's process could be useful in suggesting and demonstrating the use of convergent interviews, which could surface the relevant issues for a particular overseas context.

\section{Conclusions}

With the increasing concerns about PFASs in construction, this study surfaced the key issues impacting the management of PFAS contamination, particularly for infrastructure construction involving tunneling. With a historical lack of guidance from the EPA on the management of PFASs, and a continual increase in the volume of the contaminated soil being uncovered, it is the responsibility of the contractor to find a process to remediate or appropriately dispose of the contaminated spoil. There are established and arising technologies available for the treatment of PFASs in soils, with consideration to the volume of material, or to the degree of concentration (e.g., low volume of high concentration in acute contaminated sites, relative to high volumes of lower concentrations). At the moment, the absorption of PFASs is the main process for the removal of contamination, although electrochemical processing may end up being the most cost-effective solution in the future. Electrochemical processing can use a renewable source and it is not based on an active mineral, which may make it the most inexpensive and least disruptive approach to PFAS remediation.

The recommendations that have arisen from the results of this study are particularly useful for informing successful change because they are customized to the context. In terms of the content of the results, for Australian and Victoria, immediate steps forward for the management of PFASs include changing the enforcement and policing of regulation by the (Victorian) EPA. That is, the EPA could employ individuals with more experience in the construction industry to help establish themselves as a strong regulator, as well as review their internal processes. The use and adaptation of the IS rating system may also operationally focus the minds of industry participants, although the IS ratings were seen to be more applicable for larger organizations. To increase the rate at which change occurs, further financial incentives could be introduced on smaller-scale projects for the removal or remediation of PFASs. At the strategic level, the use of alliance models could be further 
developed on large-scale projects to enhance the research and development of treatment and reuse methods for the remediation of PFAS contamination in construction spoil.

With efforts being made by countries around the world to improve their infrastructure, including some moves towards mass transit systems and higher density living, the construction industry is facing more demands and challenges, one of which is the management of PFAS contamination. Further to the results above, the process of convergent interviewing is also recommended for other contexts that face complex situations. Inductive diagnostic methods, such as convergent interviewing, can inform the development of change programs for any given country and industry context. In Victoria, Australia, the combination of strengthened regulation enforcement, along with taking an alliance approach to projects that include IS ratings in their contracts, could dramatically improve the awareness and management of PFAS contamination in the construction industry, and could make the construction industry more sustainable.

Author Contributions: Conceptualization, K.C., B.S., J.B., S.R. and J.R.; methodology, J.R., B.S., K.C., J.B. and S.R.; formal analysis, B.S., K.C., J.B., J.R. and S.R.; investigation, B.S., K.C., J.B., J.R. and S.R.; writing—original draft preparation, K.C., B.S., J.B., S.R. and J.R.; writing—review and editing, J.R., S.R., M.N., K.C., B.S. and J.B.; supervision, S.R. and J.R. All authors have read and agreed to the published version of the manuscript.

Funding: This research received no external funding.

Institutional Review Board Statement: The research approval code from the Swinburne Human Ethics Committee was 20210537-8927, active from July 2016 to December 2021.

Informed Consent Statement: Informed consent was obtained from all subjects involved in the study.

Acknowledgments: The authors would like to acknowledge and thank the many industry professionals and their organizations who took part in the interviewing process.

Conflicts of Interest: The authors declare no conflict of interest.

\section{Appendix A. Treatment Methods}

The current treatment technologies that have been proven for the remediation of PFASs are thermal desorption and immobilization [17]. Thermal desorption is a technology that vaporizes the PFASs in soils and wastes by using high temperatures, of up to $550{ }^{\circ} \mathrm{C}$ [33]. The thermal desorption process involves three typical stages: pretreatment by screening the soil (e.g., with magnets to removal ferrous metals); heating; and removal [34]. Depending on the moisture content, material may need to be stockpiled so that it can be dried before being treated, or longer heating times will be required to initially dry the material out.

Thermal desorption has been evaluated for the removal of PFASs from soils across various temperatures for varying time periods. The contaminated soil is heated in vessels between 200 and $600{ }^{\circ} \mathrm{C}$, depending on the contaminants, which captures any volatilized PFASs [34]. Some laboratory results have suggested that substances with higher concentrations do not reduce significantly at temperatures of up to $300{ }^{\circ} \mathrm{C}$, and that it was not until $350{ }^{\circ} \mathrm{C}$ that most samples reached a $99 \%$ reduction in PFASs [35]. In order to obtain all of the types of PFASs to the target levels below $1.0 \mu \mathrm{g} / \mathrm{kg}$, the temperatures needed to be increased to $400{ }^{\circ} \mathrm{C}$ for 14 days [35].

Although thermal desorption does have the potential to remove the tested PFAS compounds from soils to safe levels, this treatment process is costly and time consuming, and the need to keep soils at $400{ }^{\circ} \mathrm{C}$ for 14 days may not be feasible with the very large quantities of contaminated soils that are being exposed by the tunneling industry. Indeed, with individual tunneling projects set to be excavating quantities of around 1700 cubic meters of potentially contaminated soils daily, it is unclear how this strategy could be scaled up to treat that quantity of waste.

The second main option for the treatment of PFAS-contaminated soils is immobilization. Immobilization is a stabilization treatment that adds sorbents to contaminated soils to contain the PFAS compounds that are present, thereby preventing leaching into the 
groundwater [36]. These additives include activated carbon, resin minerals, biomaterials, and molecularly imprinted polymers. Immobilization has been used worldwide as a costeffective option. For example, it was used for the remediation of a fire station in Sweden that used RemBind to reduce the leachability of the PFASs within the construction spoil. Treatment using RemBind requires that it be combined with the contaminated soil at a ratio of up to $5 \%$ of the stabilization product, but it is often up to only $2 \%$, with the soil moisture content adjusted if need be. The PFAS-contaminated soil was then approved by the Swedish EPA, which declared that all of the soil that was stabilized with RemBind could be relocated to the treatment plants [37]. Again, a limitation to this approach being used by the tunneling industry is the very high volumes of contaminated spoil being generated that would require huge quantities of products, such as RemBind, to stabilize.

A third recent technology that is being developed entails the electrochemical processing of PFAS contamination by altering the $\mathrm{pH}$ levels of the contaminated soils through electrodialysis in order to remove the solubility and solution charge of the soil [38]. Although only relatively recently developed, it is believed that electrochemical processing is likely to be the most cost-effective solution to immobilize PFAS contamination within soils and sediments. Furthermore, this process could use energy from a renewable source, and it does not entail putting another active chemical in the soil. Although this process was only recently applied to PFAS contamination, the general electrochemical process has been implemented in in situ trials for the remediation and immobilization of a number of other chemicals in both soils and groundwater [39-41]. However, given the newness of this approach, its viability at scale remains uncertain.

\section{References}

1. $\quad$ Buck, R.C.; Franklin, J.; Berger, U.; Conder, J.M.; Cousins, I.T.; De Voogt, P.; Jensen, A.A.; Kannan, K.; Mabury, S.A.; van Leeuwen, S.P. Perfluoroalkyl and Polyfluoroalkyl Substances in the Environment: Terminology, Classification, and Origins. Integr. Environ. Assess. Manag. 2011, 7, 513-541. [CrossRef] [PubMed]

2. Ritscher, A.; Wang, Z.; Scheringer, M.; Boucher, J.M.; Ahrens, L.; Berger, U.; Bintein, S.; Bopp, S.K.; Borg, D.; Buser, A.M. Zürich Statement on Future Actions on Per-and Polyfluoroalkyl Substances (PFASs). Environ. Health Perspect. 2018, 126, 084502. [CrossRef] [PubMed]

3. Organisation for Economic Cooperation and Development. Working towards a Global Emission Inventory of PFASS: Focus on PFCAS: Status Quo and the Way Forward; OECD: Paris, France, 2015.

4. Baabish, A.; Sobhanei, S.; Fiedler, H. Priority Perfluoroalkyl Substances in Surface Waters: A Snapshot Survey from 22 Developing Countries. Chemosphere 2021, 273, 129612. [CrossRef] [PubMed]

5. Commonwealth of Australia. International Cooperation: Per- and Poly-Fluoroalkyl Substances (PFAS). 2019. Available online: https:/ / www.pfas.gov.au/government-action/international-cooperation (accessed on 23 January 2022).

6. Australian Government Department of Health. Per- and Poly-Fluoroalkyl Substances (PFAS) Health Effects and Exposure Pathways. Available online: https:/ / www1.health.gov.au/internet/main/publishing.nsf/content/44CB8059934695D6CA258 02800245F06/\$File/health-effects-exposure-factsheet.pdf (accessed on 29 December 2021).

7. Richard, W. West Gate Tunnel Builders Seek to Terminate Contract over Contaminated Soil. Available online: https:/ /www.abc. net.au/news / 2020-01-29/west-gate-tunnel-builders-seek-to-terminate-contract-over-pfas/11909402 (accessed on 23 May 2020).

8. Going Underground. Ecogeneration 2018, 46-48. [CrossRef]

9. Di Nauta, M.; Anders, A.; Zapico, C.S. Forrestfield Airport Link Project-Variable Density TBMs to Deal with Unexpected Ground Conditions. In Tunnels and Underground Cities: Engineering and Innovation meet Archaeology, Architecture and Art; CRC Press: Boca Raton, FL, USA, 2019; pp. 2051-2060.

10. Victoria's Big Build. About Us. Available online: https://bigbuild.vic.gov.au/about (accessed on 5 April 2020).

11. Craig, B. Technical Advice-Contamination-Final Report; North East Link Project IAC: Melbourne, Australia, 2019 ; pp. 1-63.

12. Timna, J. Secret EPA Reports Reveal PFAS Problem on West Gate Tunnel. Available online: https://www.theage.com.au/national/ victoria/secret-epa-reports-reveal-pfas-problem-on-west-gate-tunnel-20200523-p54vr1.html (accessed on 24 May 2020).

13. Environmental Protection Agency Victoria. About PFAS. Available online: https:/ /www.epa.vic.gov.au/pfas (accessed on 29 December 2021).

14. Benjamin, P. Coronavirus Australia: New EPA Powers Delayed by a Year in COVID-19 “Omnibus" Bill. Available online: https:/ / www.theage.com.au/national/victoria/new-epa-powers-delayed-by-a-year-in-coronavirus-omnibus-bill-2020 0505-p54q2d.html (accessed on 5 May 2020).

15. Environmental Protection Agency Victoria. Regulatory Strategy: 2020-2025 Draft; Environmental Protection Agency Victoria: Carlton, Australia, 2019. 
16. Environmental Protection Agency Victoria. Permissions Scheme; Environmental Protection Agency Victoria: Carlton, Australia, 2019.

17. National Chemicals Working Group of the Heads of EPAs Australia and New Zealand. PFAS National Environmental Management Plan Version 2.0-January 2020; Heads of EPAs Australia and New Zealand (HEPA): Canberra, Australia, 2020.

18. CEEQUAL. CEEQUAL Version 5.1, Assessment Manual for Projects; CEEQUAL: Watford, UK, 2013.

19. Infrastructure Sustainability Council of Australia. Infrastructure Sustainability Rating Tool Technical Manual, Version 1.0; Infrastructure Sustainability Council of Australia: Sydney, Australia, 2013.

20. Infrastructure Sustainability Council of Australia. ISCA Strategic Plan: 2020 to 2025; Infrastructure Sustainability Council of Australia: Sydney, Australia, 2020.

21. Infrastructure Sustainability Council of Australia. ISv2.0 Release Information; Infrastructure Sustainability Council of Australia: Sydney, Australia, 2018.

22. Infrastructure Sustainability Council of Australia. Infrastructure Sustainability Rating Tool Technical Manual, Version 2.0; Infrastructure Sustainability Council of Australia: Sydney, Australia, 2018

23. Griffiths, K.; Boyle, C.; Henning, T.F. Beyond the Certification Badge-How Infrastructure Sustainability Rating Tools Impact on Individual, Organizational, and Industry Practice. Sustainability 2018, 10, 1038. [CrossRef]

24. Infrastructure Sustainability Council of Australia. IS Rating Scheme Return on Investment; Infrastructure Sustainability Council of Australia: Sydney, Australia, 2020.

25. Jepsen, D.M.; Rodwell, J.J. Convergent Interviewing: A Qualitative Diagnostic Technique for Researchers. Manag. Res. News 2008, 31, 650-658. [CrossRef]

26. Thynne, L.; Rodwell, J. A Pragmatic Approach to Designing Changes Using Convergent Interviews: Occupational Violence against Paramedics as an Illustration. Aust. J. Public Adm. 2018, 77, 272-279. [CrossRef]

27. Dick, R. Convergent Interviewing; Interchange: Brisbane, Australia, 1990.

28. Williams, W.; Lewis, D. Convergent Interviewing: A Tool for Strategic Investigation. Strat. Change 2005, 14, 219-229. [CrossRef]

29. Thynne, L.; Rodwell, J. Diagnostic Convergent Interviewing to Inform Redesign toward Sustainable Work Systems for Paramedics. Sustainability 2019, 11, 3932. [CrossRef]

30. Boland, T.; Fowler, A. A Systems Perspective of Performance Management in Public Sector Organisations. Int. J. Pub. Sector Man. 2000, 13, 417-446. [CrossRef]

31. Australian Government Department of Infrastructure and Regional Development. National Alliance Contracting Guidelines. Guide to Alliance Contracting; Australian Government Department of Infrastructure and Regional Development: Canberra, Australia, 2015.

32. Griffiths, K.; Boyle, C.; Henning, T.F. Infrastructure Sustainability Rating Tools-Exploring Opportunities for the Engineering Profession Based on International Research. Aust. J. Civ. Eng. 2020, 18, 18-28. [CrossRef]

33. Sörengård, M.; Lindh, A.S.; Ahrens, L. Thermal Desorption as a High Removal Remediation Technique for Soils Contaminated with Per-and Polyfluoroalkyl Substances (PFASs). PLoS ONE 2020, 15, e0234476. [CrossRef] [PubMed]

34. CRC for Contamination Assessment and Remediation of the Environment (CRC Care). National Remediation Framework. Technology Guide: Thermal Desorption; CRC Care: Callaghan, Australia, 2018.

35. Crownover, E.; Oberle, D.; Kluger, M.; Heron, G. Perfluoroalkyl and Polyfluoroalkyl Substances Thermal Desorption Evaluation. Remediat. J. 2019, 29, 77-81. [CrossRef]

36. Mahinroosta, R.; Senevirathna, L. A Review of the Emerging Treatment Technologies for PFAS Contaminated Soils. J. Environ. Manag. 2020, 255, 109896. [CrossRef] [PubMed]

37. RemBind. PFAS Remediation at a Former Metal Plating Factory in Sweden. Available online: https://rembind.com/projects/ pfas-remediation-at-a-former-metal-plating-factory-in-sweden/ (accessed on 29 December 2021).

38. Sörengård, M.; Niarchos, G.; Jensen, P.E.; Ahrens, L. Electrodialytic Per-and Polyfluoroalkyl Substances (PFASs) Removal Mechanism for Contaminated Soil. Chemosphere 2019, 232, 224-231. [CrossRef] [PubMed]

39. Jeon, E.-K.; Jung, J.-M.; Kim, W.-S.; Ko, S.-H.; Baek, K. In Situ Electrokinetic Remediation of As-, Cu-, and Pb-Contaminated Paddy Soil Using Hexagonal Electrode Configuration: A Full Scale Study. Environ. Sci. Pollut. Res. 2015, 22, 711-720. [CrossRef] [PubMed]

40. Kim, B.-K.; Baek, K.; Ko, S.-H.; Yang, J.-W. Research and Field Experiences on Electrokinetic Remediation in South Korea. Sep. Purif. Technol. 2011, 79, 116-123. [CrossRef]

41. Kim, W.-S.; Park, G.-Y.; Kim, D.-H.; Jung, H.-B.; Ko, S.-H.; Baek, K. In Situ Field Scale Electrokinetic Remediation of Multi-Metals Contaminated Paddy Soil: Influence of Electrode Configuration. Electrochim. Acta 2012, 86, 89-95. [CrossRef] 